\title{
A rare case of poorly differentiated endocrine cell carcinoma of the stomach with signet ring cell differentiation
}

\author{
Souya Nunobe ${ }^{1,2}$, Hirokazu Taniguchi ${ }^{1}$, Hitoshi Katai $^{2}$, and Tadakazu Shimoda ${ }^{1}$ \\ ${ }^{1}$ Clinical Laboratory Division, National Cancer Center Central Hospital, 5-1-1 Tsukiji, Chuo-ku, Tokyo 104-0045, Japan \\ ${ }^{2}$ Division of Surgery, National Cancer Center Hospital, Tokyo, Japan
}

\begin{abstract}
There have been few reports of the dual differentiation of different cell types within the same gastric tumor. Here, we report a rare case of poorly differentiated endocrine cell carcinoma with an associated differentiated signet ring cell population arising in the stomach. The histological appearance of the tumor by light microscopy matched the phenotype of endocrine cell carcinoma and signet ring cell differentiation with mucinous lakes. Cells with a phenotype intermediate between the two differentiated cell types were also seen in the tumor. Both the endocrine cell carcinoma and the signet ring cells were diffusely positive for chromogranin $A$ and synaptophysin, a finding that is consistent with endocrine differentiation by immunohistochemical examination. The patient's postoperative clinical course had a poor prognosis, with aggressive tumor progression. Paraaortic lymph node recurrence was found 6 months after the operation, and the patient died of the primary disease 16 months after the surgical treatment.
\end{abstract}

Key words Gastric cancer · Poorly differentiated adenocarcinoma $\cdot$ Endocrine cell carcinoma $\cdot$ Dual differentiation

\section{Introduction}

Many epithelial tumors of the gastrointestinal tract are not homogeneous and retain admixtures of different epithelial cells, including glandular epithelium, endocrine, and Paneth cells. Studies of embryological development have shown that gastrointestinal epithelial cells and endocrine cells are derived from a common stem cell [1-3]. Poorly differentiated endocrine cell carcinoma (PDECC), which is a rare and unpredictable tumor, occasionally shows multidirectional differentiation with adenocarcinoma and/or squamous cell prolif-

Offprint requests to: $\mathrm{T}$. Shimoda

Received: August 17, 2009 / Accepted: December 25, 2009 eration [4-6]. PDECCs of the stomach are classified as either a pure-type tumor $(42 \%)$ or a composite-type tumor $(58 \%)$ containing an admixture of adenocarcinoma and/or differentiated squamous type cells [7]. In almost all PDECCs the adenomatous components of composite-type tumors are well-differentiated adenocarcinomas; however, rare cases of PDECCs have poorly differentiated adenocarcinomas, including signet ring cell carcinomas [7-9].

Tumors that exhibit dual differentiation; for example, showing both mucus production and dense core granules within the cytoplasm of the same cell, are extremely rare even among composite-type tumors [10]. A very few cases of such tumors involving the stomach have been reported previously, although the peculiar biological behavior has not been described in detail $[7,11]$.

Here, we describe a rare case of a tumor, with lymph node metastasis, showing dual differentiation composed of PDECC of the stomach containing differentiated signet ring cells, which had a poor prognosis with aggressive tumor progression.

\section{Case report}

A 70-year-old woman was referred to hospital with a positive fecal occult blood test. Endoscopic examination revealed an ulcerated lesion located in the middle third of the stomach, which was diagnosed as a histologically benign ulcer. The patient was followed on an outpatient basis and on the third endoscopic examination, a gastric adenocarcinoma was confirmed by biopsy. Computed tomography (CT) and ultrasonography showed a lymph node measuring $10 \mathrm{~mm}$ in diameter on the lesser curve of the stomach that was suggestive of metastasis, but no metastases at distant sites including the liver were identified. Laboratory tumor markers were slightly elevated, with a carcinoembryonic antigen (CEA) level of $8.0 \mathrm{ng}$ / $\mathrm{ml}$ (normal range $[\mathrm{NR}]<5.0 \mathrm{ng} / \mathrm{ml}$ ) and carbohydrate 
antigen 19-9 (CA19-9) of $52 \mathrm{U} / \mathrm{ml}(\mathrm{NR}<37 \mathrm{U} / \mathrm{ml})$. Twelve months after the initial diagnosis, the patient underwent a distal gastrectomy with lymph node dissection. The postoperative course was uneventful and the patient was discharged 11 days after the surgery.

CT examination performed 6 months after the surgery revealed lymph node recurrence of the tumor around the abdominal aorta. TS- 1 chemotherapy achieved a partial response at 8 months after the surgery, but the patient died of lymph node metastases and peritoneal dissemination 16 months after the surgical treatment.

\section{Methods}

Tissue specimens were fixed in $4 \%$ formaldehyde and processed to paraffin-embedded sections. The slides, stained with hematoxylin and eosin (H \& E) and alcian blue-periodic acid-Schiff (AB-PAS), were evaluated by the Grimelius method. Labeled streptavidin biotin (LSAB) immunohistochemistry was performed on $3-\mu \mathrm{m}$ tissue sections using an i6000 automated staining system (BioGenex, San Ramon, CA, USA). Representative slides were deparaffinized and stained using the following antibodies: chromogranin A (Dako Japan, Kyoto, Japan; polyclonal, diluted 1: 500), synaptophysin (Dako; polyclonal, diluted 1:100), MUC2 (Ccp58; Novocastra Laboratories, Newcastle, UK; monoclonal, diluted 1: 200), and Cdx2 (CDX2-88; BioGenex; monoclonal, diluted 1: 200). For negative controls, similar dilutions of control mouse IgG1 were substituted for the antibody.

\section{Pathological findings}

Histological examination of the resected specimen revealed a large ulcerated tumor, measuring $3.7 \times$ $3.5 \mathrm{~cm}$, located in the distal stomach, with serosal invasion and lymphatic and neural involvement. Metastases were also found in the second-tier lymph nodes (nodes according to the Japanese classification of gastric carcinoma) [12].

$\mathrm{H} \& \mathrm{E}$ staining showed a tumor histologically comprised of two components: (i) an endocrine cell carcinoma containing poorly differentiated cells with diffuse granular cytoplasm arranged in cord-like structures and (ii) a signet ring cell component forming mucinous lakes (Fig. 1 A, B, C). There were also transitional areas between the two different types of tumor cells.

Immunohistochemical examination showed that both the endocrine cell carcinoma cells and signet ring tumor cells were diffusely positive for chromogranin A and synaptophysin (Fig. 2 A, B). Mucin within the cytoplasm of goblet cells was positive for MUC2.

\section{Discussion}

Extrapulmonary malignant neoplasms composed largely or entirely of small neoplastic cells with a markedly hyperchromatic nucleus and scanty cytoplasm have been described as small cell carcinoma [4, $7,9]$, neuroendocrine carcinoma [13, 14], anaplastic carcinoma [15], or small cell epidermoid carcinoma [16]. Unlike lung cancer, extrapulmonary neoplasms of this type are uncommon but have been reported in a variety of other organs $[4,7-9,13,15]$. Although PDECCs of the stomach are extremely rare, we want to emphasize the importance of recognizing this tumor as a specific type of cancer. PDECCs have distinct phenotypic activity characterized by early invasion and metastases, and are frequently associated with paraendocrine syndromes [7-9]. In our patient, the case of PDECC of the stomach was characterized by an aggressive clinical course, with a poor prognosis involving paraaortic lymph node metastases 6 months after surgery, resulting in death 10 months after the relapse, despite chemotherapy.

PDECC of the stomach is classified as either a puretype tumor or a composite-type tumor with an admixture of adenocarcinomatous cells and/or differentiated squamous cells [7]. Most cases of the composite-type of PDECC have a well-differentiated adenocarcinomatous component in the mucosal layer. Only one case of a composite-type PDECC tumor with dual differentiation of an adenomatous component positive for chromogranin has been reported previously. That report described a PDECC with signet ring cell differentiation, and both cell types were immunohistochemically positive for chromogranin and synaptophysin, as in the case we have described here. PDECC of the stomach associated with poorly differentiated adenocarcinoma would be a significant finding in the analysis of PDECC progression, but unfortunately this previously reported case was not described in detail.

Composite epithelial tumors can be classified according to the Armed Forces Institute of Pathology (AFIP) criteria [10] as:

1) Carcinomas interspersed with endocrine cells

2) Carcinoids interspersed with nonendocrine cells

3) Composite glandular-endocrine cell carcinomas tumors consisting of discrete areas of carcinoma (with any degree of differentiation) and carcinoid (with any degree of differentiation)

4) Collision tumors, in which endocrine tumors and adenocarcinomas are closely juxtaposed but not admixed

5) Amphicrine tumors composed predominantly of cells that exhibit dual differentiation; for example, 


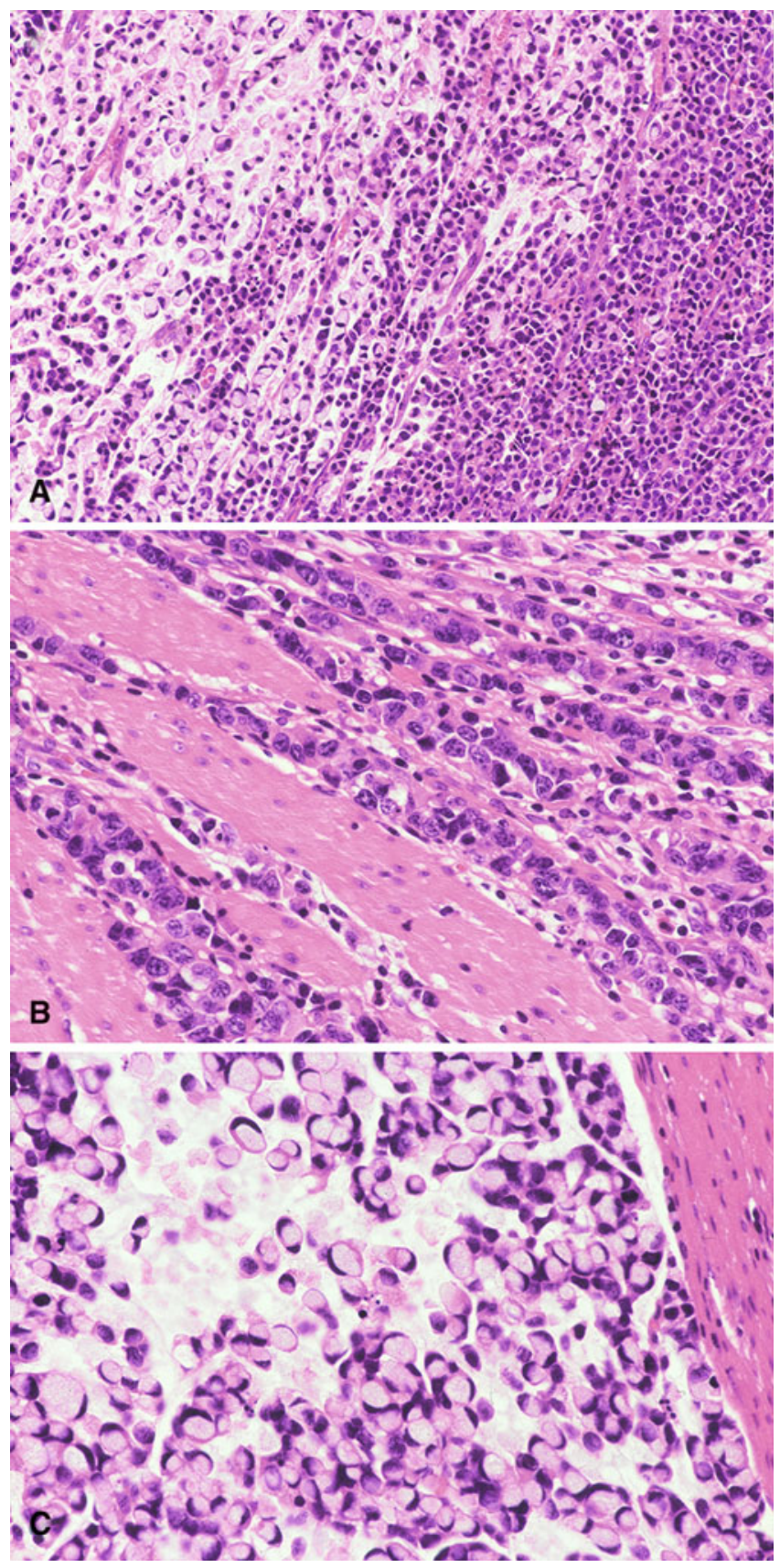

Fig. 1. A Poorly differentiated endocrine cell carcinoma with signet ring cell differentiation. The tumor has two components; poorly differentiated endocrine cell carcinoma and signet ring cell carcinoma with transitional areas. B Poorly differentiated endocrine cells with diffuse granular cytoplasm with a desmoplastic reaction arranged in cord-like structures. C Signet ring cell component forming mucinous lakes. A $\mathrm{H} \& \mathrm{E}, \times 120 ; \mathbf{B}$ and $\mathbf{C} \mathrm{H} \& \mathrm{E}, \times 300$

mucus and dense core granules within the cytoplasm of the same cell

6) Combination tumors of the above types.

Of these six types of tumors, the amphicrine tumors are extremely rare and only one case has been described

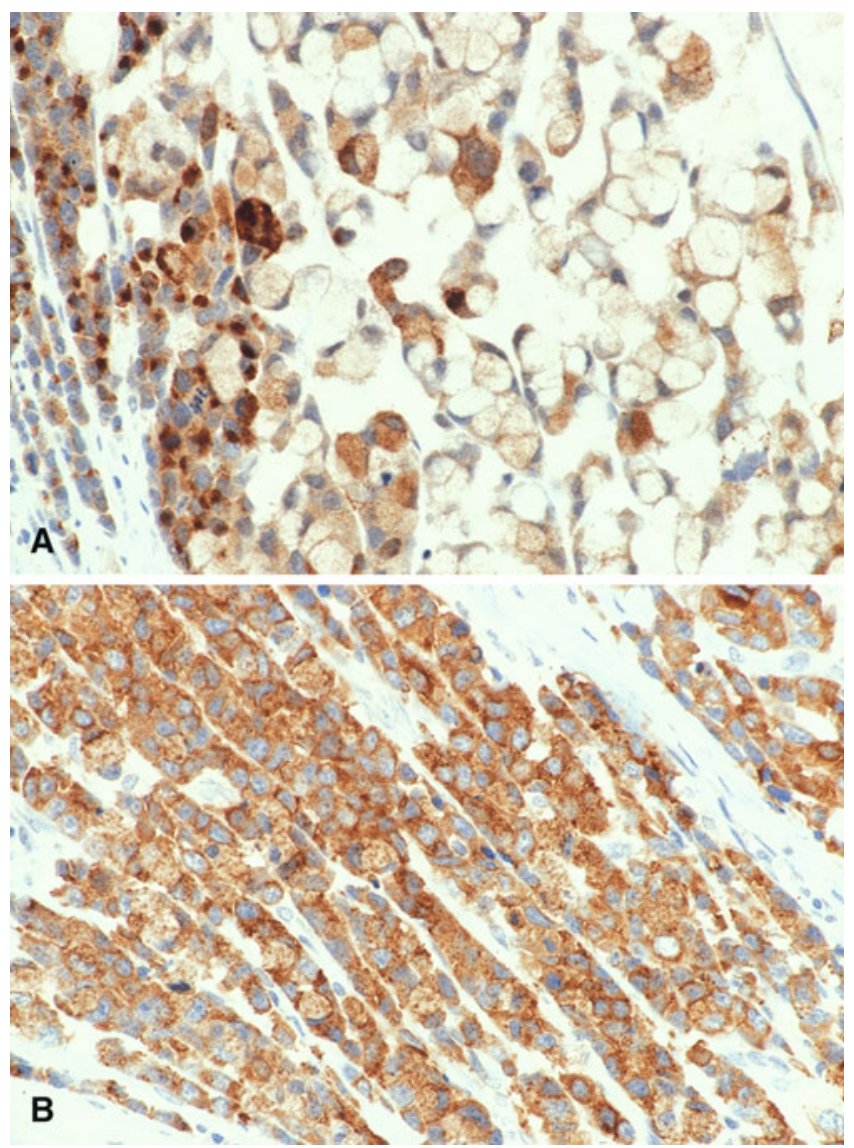

Fig. 2. A Chromogranin A is diffusely expressed in the cytoplasm of each poorly differentiated endocrine cell carcinoma (PDECC) and signet ring cell carcinoma. B Synaptophysin is also diffusely expressed in the cytoplasm of PDECC cells. Signet ring tumor cells show scattered synaptophysin staining. $\times 300$

in the stomach; this had only one component with a combination of well-differentiated adenocarcinoma and carcinoid [11]. Amphicrine tumors described by the AFIP criteria showed two types of intracytoplasmic granules, including small electron-dense granules and large lucent mucin droplets, on electron microscopy. The present case is important for pathologists assessing PDECCs for the presence of neuroendocrine differentiation, particularly for tumors that do not display characteristic argyrophilia or ultrastructural neurosecretory granules. The recognition of these types of tumors of the stomach is imperative in view of their aggressive biological behavior with an associated poor prognosis irrespective of treatment modalities. Therefore, both histochemical and immunohistochemical evaluation of the tumor is necessary for the pathological diagnosis of a gastric endocrine tumor.

Goblet cell carcinoid, which is a distinctive appendiceal neoplasm exhibiting both neuroendocrine and glandular differentiation, has been reported to display 
a spectrum of histological features and to possess the potential to transform to an adenocarcinoma phenotype of either signet ring cell or poorly differentiated adenocarcinoma type as a subclassification of tumors [17]. Tang et al. [17] also reported that their clinical outcome could be differentiated by subclassification of tumors, and the survival of goblet cell carcinoid of poorly differentiated adenocarcinoma type was dismal. Also, neoplastic cells of signet ring cell carcinoma in gastric cancer sometimes show endocrine cell differentiation [18]. Bakkelund et al. [18] reported that signet ring cell carcinomas could be of neuroendocrine origin, and they proposed, from their immunohistochemical investigation of signet ring cells in gastric carcinomas, that signet ring cell carcinomas develop by gradual differentiation from enterochromaffin-like cells, via signet ring cells with neuroendocrine immunoreactivity, toward signet ring cells. We suggest that, from its unique pathological features and clinical behavior, the present case might be a subtype of signet ring cell carcinoma with neuroendocrine immunoreactivity.

\section{References}

1. Andrew A. Further evidence that enterochromaffin cells are not derived from the neural crest. J Embryol Exp Morphol 1974; 31:589-98.

2. LeDouarin NM. The embryological origin of the endocrine cells associated with the digestive tract: experimental analysis based on the use of a stable cell marking technique. In: Bloom SR, editor. Gut hormones. Edinburgh: Churchill Livingstone; 1978. p. 49-56.

3. Pictet RL, Rall LB, Phelps P, Rutter WJ. The neural crest and the origin of the insulin-producing and other gastrointestinal hormone-producing cells. Science 1976;191:191-2.

4. Mori M, Matsukuma A, Adachi Y, Miyagahara T, Matsuda H, Kuwano H, et al. Small cell carcinoma of the esophagus. Cancer 1989;63:564-73.
5. Fukuda T, Ohnishi Y, Nishimaki T, Ohtani H, Tachikawa S. Early gastric cancer of the small cell type. Am J Gastroenterol 1988;83:1176-9.

6. Saba SR, Azar HA, Richman AV, Solomon DA, Spurlock RG, Mardelli IG, et al. Dual differentiation in small cell carcinoma (oat cell carcinoma) of the lung. Ultrastruct Pathol 1981;2:131-8.

7. Matsui K, Kitagawa M, Miwa A, Kuroda Y, Tsuji M. Small cell carcinoma of the stomach: a clinicopathologic study of 17 cases. Am Coll Gastroenterol 1991;86:1167-75.

8. Rindi G, Azzoni C, LaRosa S, Klersy C, Paolotti D, Rappel S, et al. ECL cell tumor and poorly differentiated endocrine carcinoma of the stomach: Prognostic evaluation by pathological analysis. Gastroenterology 1999;116:532-42.

9. Namikawa T, Kobayashi M, Okabayashi T, Ozaki S, Nakamura S, Yamashita K, et al. Primary gastric small cell carcinoma: report of a case and review of the literature. Med Mol Morphol 2005; 38:256-61.

10. Lewin KJ, Appelman HD. Tumors of the esophagus and stomach. Atlas of tumor pathology, third series, fascicle 18. Washington, DC: Armed Forces Institute of Pathology; 1996. p. 352.

11. Ali MH, Davidson A, Azzopardi JG. Composite gastric carcinoid and adenocarcinoma. Histopathology 1984;8:529-36.

12. Japanese Gastric Cancer Association. Japanese classification of gastric carcinoma. - 2nd English edition -. Gastric Cancer 1998; 1:10-24.

13. Reyes CV, Chejfec G, Jao W, Gould VE. Neuroendocrine carcinoma of the esophagus. Ultrastruct Pathol 1980;1:367-76.

14. Chejfec G, Gould VE. Malignant gastric neuroendocrinomas. Hum Pathol 1977;8:433-40.

15. Matsusaka T, Watanabe H, Enjoji M. Anaplastic carcinoma of the esophagus. Report of three cases and their histogenetic consideration. Cancer 1976;37:1352-8.

16. Shibuya H, Azumi N, Abe F. Gastric small cell undifferentiated carcinoma with adeno- and squamous cell carcinoma components. Acta Pathol Jpn 1985;35:473-80.

17. Tang LH, Shia J, Soslow RA, Dhall D, Wong WD, O'Reilly E, et al. Pathologic classification and clinical behavior of the spectrum of goblet cell carcinoid tumors of the appendix. Am J Surg Pathol 2008;32:1429-43.

18. Bakkelund K, Fossmark R, Nordrum I, Waldum H. Signet ring cells in gastric carcinomas are derived from neuroendocrine cells. J Histochem Cytochem 2006;54:615-21. 